\title{
Comparison of Somatostatin Receptor Agonist and Antagonist for Peptide Receptor Radionuclide Therapy: A Pilot Study
}

\author{
Damian Wild ${ }^{1,2}$, Melpomeni Fani ${ }^{1,2}$, Richard Fischer ${ }^{3}$, Luigi Del Pozzo ${ }^{1}$, Felix Kaul ${ }^{1,2}$, Simone Krebs ${ }^{1}$, Richard Fischer ${ }^{1}$, \\ Jean E.F. Rivier ${ }^{4}$, Jean Claude Reubi ${ }^{5}$, Helmut R. Maecke ${ }^{1,6}$, and Wolfgang A. Weber ${ }^{1,6,7}$ \\ ${ }^{1}$ Department of Nuclear Medicine, University Hospital Freiburg, Freiburg, Germany; ${ }^{2}$ Division of Nuclear Medicine, University of \\ Basel Hospital, Basel, Switzerland; ${ }^{3}$ Oncology "Dreiländereck," Lörrach, Germany; ${ }^{4}$ Clayton Foundation Laboratories for Peptide \\ Biology, Salk Institute, La Jolla, California, ${ }^{5}$ Division of Cell Biology and Experimental Cancer Research, Institute of Pathology, \\ University of Berne, Berne, Switzerland; ${ }^{6}$ German Cancer Consortium (DKTK), Freiburg, Germany; and ${ }^{7}$ Department of Radiology, \\ Sloan-Kettering Cancer Center, New York, New York
}

Preclinical and clinical studies have indicated that somatostatin receptor (sst)-expressing tumors demonstrate higher uptake of radiolabeled sst antagonists than of sst agonists. In 4 consecutive patients with advanced neuroendocrine tumors, we evaluated whether treatment with ${ }^{177} \mathrm{Lu}$-labeled sst antagonists is feasible. Methods: After injection of approximately $1 \mathrm{GBq}$ of ${ }^{177} \mathrm{Lu}$-DOTA-[Cpa-c(DCys-Aph(Hor)DAph(Cbm)-Lys-Thr-Cys)-DTyr-NH ${ }_{2}$ ( ${ }^{177}$ Lu-DOTA-JR11) and ${ }^{177} \mathrm{Lu}-$ DOTATATE, 3-dimensional voxel dosimetry analysis based on SPECT/CT was performed. A higher tumor-to-organ dose ratio for ${ }^{177} \mathrm{Lu}$-DOTAJR11 than for ${ }^{177}$ Lu-DOTATATE was the prerequisite for treatment with ${ }^{177}$ Lu-DOTA-JR11. Results: Reversible minor adverse effects of ${ }^{177}$ Lu-DOTA-JR11 were observed. ${ }^{177}$ Lu-DOTA-JR11 showed a 1.7-10.6 times higher tumor dose than ${ }^{177}$ Lu-DOTATATE. At the same time, the tumor-to-kidney and tumor-to-bone marrow dose ratio was 1.1-7.2 times higher. All 4 patients were treated with ${ }^{177}$ Lu-DOTA-JR11, resulting in partial remission in 2 patients, stable disease in 1 patient, and mixed response in the other patient. Conclusion: Treatment of neuroendocrine tumors with radiolabeled sst antagonists is clinically feasible and may have a significant impact on peptide receptor radionuclide therapy.

Key Words: antagonists; neuroendocrine tumors; somatostatin receptor targeting

J Nucl Med 2014; 55:1248-1252

DOI: 10.2967/jnumed.114.138834

\section{$\mathbf{R}$} adiolabeled somatostatin receptor (sst) agonists, for example, ${ }^{177} \mathrm{Lu}$-DOTATATE, have become an integral part of therapeutic management in patients with neuroendocrine tumors (1). Radiolabeled sst antagonists are not established for tumor targeting, mainly because they do not internalize into tumor cells. Ginj et al., however, were the first to show in animal studies that radiolabeled sst antagonists are superior to agonists for targeting of tumors (2). A possible explanation may be that antagonists bind to a larger population of binding sites than agonists (2). Scatchard analysis in sst subtype $2\left(\mathrm{sst}_{2}\right)$-transfected HEK293 cells showed more than 10 times

Received Feb. 10, 2014; revision accepted May 9, 2014.

For correspondence contact: Damian Wild, Division of Nuclear Medicine, University of Basel Hospital, Petersgraben 4, CH-4031 Basel, Switzerland.

E-mail: damian.wild@usb.ch

Published online Jun. 24, 2014

COPYRIGHT (C) 2014 by the Society of Nuclear Medicine and Molecular Imaging, Inc. the number of binding sites for the sst antagonist ${ }^{111} \mathrm{In}$-DOTA-[p$\mathrm{NO}_{2}$-Phe-c(DCys-Tyr-DTrp-Lys-Thr-Cys)-DTyr-NH $\mathrm{N}_{2}$ ( ${ }^{111}$ In-DOTABASS) than for the sst agonist $\left[{ }^{111} \mathrm{In}_{-}-\mathrm{DTPA}^{0}, \mathrm{Tyr}^{3}, \mathrm{Thr}^{8}\right]$-octreotide. Furthermore, in vitro receptor autoradiography showed about 4 times higher accumulation of ${ }^{177} \mathrm{Lu}$-DOTA-BASS in sst $_{2}$-expressing human tumor samples than did the sst agonist (3). These results were confirmed clinically in a pilot imaging study with ${ }^{111}$ In-DOTABASS and ${ }^{111}$ In-pentetreotide ( ${ }^{111}$ In-DTPA-octreotide) (4). Unfortunately, ${ }^{111}$ In-DOTA-BASS has a relatively low $\mathrm{sst}_{2}$ affinity (2). To overcome this problem, the next generation of sst antagonists was synthesized to improve the receptor affinity. From a small library, ${ }^{177}$ Lu-DOTA-[Cpa-c(DCys-Aph(Hor)-DAph(Cbm)-Lys-Thr-Cys)DTyr- $\mathrm{NH}_{2}$ ] ( $\left.{ }^{177} \mathrm{Lu}-\mathrm{DOTA}-J R 11\right)$ showed the highest $\mathrm{sst}_{2}$ affinity (5).

The purpose of this pilot study was to evaluate the feasibility of peptide receptor radionuclide therapy with the novel sst antagonist ${ }^{177} \mathrm{Lu}-\mathrm{DOTA}-J R 11$. Before treatment, tumor and organ doses of ${ }^{177} \mathrm{Lu}-$ DOTATATE and ${ }^{177} \mathrm{Lu}$-DOTA-JR11 were compared in the same patient after injection of a nontherapeutic test dose. A higher tumor-toorgan dose ratio for ${ }^{177} \mathrm{Lu}$-DOTA-JR11 than for ${ }^{177} \mathrm{Lu}$-DOTATATE was the prerequisite for treatment with ${ }^{177} \mathrm{Lu}$-DOTA-JR11.

\section{MATERIALS AND METHODS}

\section{Patients}

Four consecutive patients with progressive neuroendocrine tumors and limited treatment options due to chronic grade 2 or 3 kidney disease were prospectively recruited. Patient characteristics are summarized in Table 1. Exclusion criteria were concurrent antitumor treatment (octreotide [Sandostatin; Novartis Pharmaceuticals] depot less than $4 \mathrm{wk}$ before test injection and treatment), preexisting grade 3 and 4 hematologic toxicity, and pregnancy or breastfeeding. The institutional review board approved this study, and all subjects gave written informed consent in accordance with the Declaration of Helsinki.

\section{Radiochemistry}

DOTA-JR11 was synthesized as previously described (5). DOTATATE was received from piChem (Austria). For the preparation of ${ }^{177} \mathrm{Lu}-$ DOTA-JR11 and ${ }^{177} \mathrm{Lu}$-DOTATATE, the corresponding peptide conjugate was dissolved in $500 \mu \mathrm{L}$ of ascorbate buffer, $\mathrm{pH} 5.0$, and ${ }^{177} \mathrm{LuCl}_{3}$ was added. The solution was incubated at $95^{\circ} \mathrm{C}$ for $30 \mathrm{~min}$. Quality control was performed by analytic reverse-phase high-performance liquid chromatography on a Phenomenex Jupiter C18 4- $\mu \mathrm{m}, 250 \times 4.6 \mathrm{~mm}$ column (eluents, $\mathrm{A}=0.1 \%$ trifluoroacetic acid in water and $\mathrm{B}=$ acetonitrile; gradient, $0-25 \mathrm{~min}, 95 \%-50 \% \mathrm{~A}$; flow, $0.75 \mathrm{~mL} / \mathrm{min}$ ). The labeling yield of ${ }^{177} \mathrm{Lu}$-DOTATATE and ${ }^{177} \mathrm{Lu}$-DOTA-JR11 was more than $99 \%$ and the radiochemical purity of ${ }^{177}$ Lu-DOTA-JR11 was at least $93 \%$. 
TABLE 1

Characteristics of Patients with Neuroendocrine Tumors and Chronic Kidney Insufficiency

\begin{tabular}{|c|c|c|c|c|}
\hline Characteristic & Patient 1 & Patient 2 & Patient 3 & Patient 4 \\
\hline Age (y) & 77 & 74 & 44 & 74 \\
\hline Sex & $\mathrm{F}$ & $\mathrm{M}$ & $\mathrm{F}$ & $\mathrm{F}$ \\
\hline Diagnosis & $\begin{array}{l}\text { Neuroendocrine } \\
\text { carcinoma (bladder) }\end{array}$ & $\begin{array}{l}\text { Neuroendocrine } \\
\text { tumor (lung) }\end{array}$ & $\begin{array}{l}\text { Neuroendocrine } \\
\text { tumor (ileum) }\end{array}$ & $\begin{array}{c}\text { Neuroendocrine } \\
\text { tumor (ileum) }\end{array}$ \\
\hline Tumor grade & G3 & G1 & $\mathrm{G} 2$ & $\mathrm{G} 2$ \\
\hline First diagnosed & 5 mo ago & 3 y ago & 5 y ago & $11 \mathrm{mo}$ ago \\
\hline \multicolumn{5}{|l|}{ Pretreatment evaluation } \\
\hline ECOG performance status & 2 & 0 & 1 & 0 \\
\hline Remission status ${ }^{\star}$ & PD & PD & PD & PD \\
\hline Chronic kidney disease ${ }^{\dagger}$ & Grade 3 & Grade 3 & Grade 2 & Grade 3 \\
\hline \multicolumn{5}{|l|}{ Three-mo follow-up } \\
\hline ECOG performance status & 2 & 0 & 0 & 0 \\
\hline Remission status* & Mixed response & PR & SD & PR \\
\hline Chronic kidney disease ${ }^{\dagger}$ & Grade 3 & Grade 3 & Grade 2 & Grade 3 \\
\hline \multicolumn{5}{|l|}{ Adverse events $\ddagger$} \\
\hline Anemia (reversible) & Grade 2 & Grade 1 & Grade 2 & Grade 2 \\
\hline Leukopenia (reversible) & Grade 2 & Grade 1 & Grade 2 & Grade 0 \\
\hline $\begin{array}{l}\text { Thrombocytopenia } \\
\text { (reversible) }\end{array}$ & Grade 0 & Grade 3 & Grade 0 & Grade 0 \\
\hline Maximum follow-up (mo) & 15 & 12 & 13 & 12 \\
\hline Remission status $^{\dagger}$ & PD & PR & SD & PR \\
\hline
\end{tabular}

${ }^{*}$ Response was assessed with CT according to the Response Evaluation Criteria in Solid Tumors, version 1.1.

${ }^{\dagger}$ Chronic kidney disease was graded according to the guidelines of the National Kidney Foundation.

${ }^{\ddagger}$ Adverse events were graded according to the Common Terminology Criteria for Adverse Events, version 4.0, of the National Cancer Institute.

$\mathrm{ECOG}=$ Eastern Cooperative Oncology Group; PD = progressive disease; PR = partial response; SD = stable disease.

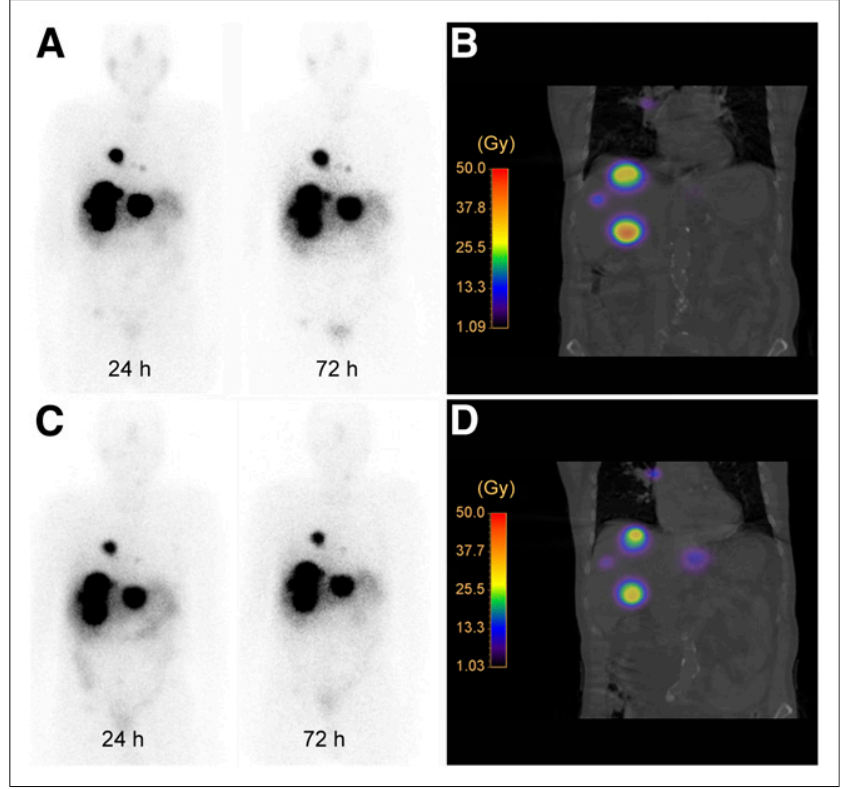

FIGURE 1. ${ }^{177}$ Lu-DOTA-JR11 planar scans (A) and isodose curves (B) of patient 2 after injection of $1,065 \mathrm{MBq}$ of ${ }^{177}$ Lu-DOTA-JR11 and corresponding ${ }^{177}$ Lu-DOTATATE planar scans (C) and isodose curves (D) after injection of $1,115 \mathrm{MBq}$ of ${ }^{177}$ Lu-DOTATATE. Planar scans (A and C) show results 24 and $72 \mathrm{~h}$ after injection of ${ }^{177}$ Lu-DOTA-JR11 and ${ }^{177}$ Lu-DOTATATE.

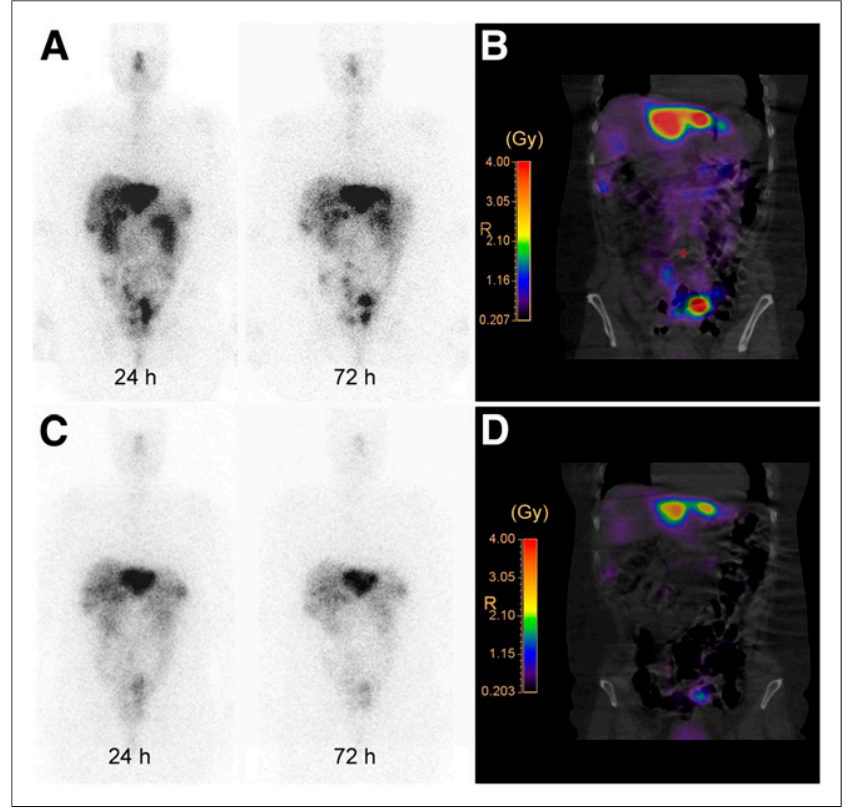

FIGURE 2. ${ }^{177}$ Lu-DOTA-JR11 planar scans (A) and isodose curves (B) of patient 3 after injection of $850 \mathrm{MBq}$ of ${ }^{177} \mathrm{Lu}$-DOTA-JR11 and corresponding ${ }^{177}$ Lu-DOTATATE planar scans $(C)$ and isodose curves (D) after injection of $990 \mathrm{MBq}$ of ${ }^{177}$ Lu-DOTATATE. Planar scans (A and C) show results 24 and $72 \mathrm{~h}$ after injection of ${ }^{177}$ Lu-DOTA-JR11 and ${ }^{177}$ Lu-DOTATATE. 
TABLE 2

Summary of Tumor Dose Calculations and Treatment Response of Delineable Tumors

\begin{tabular}{|c|c|c|c|c|c|c|c|c|c|c|c|}
\hline \multirow[b]{3}{*}{ Tumor no. } & \multirow[b]{3}{*}{$\begin{array}{l}\text { Tumor } \\
\text { site }\end{array}$} & \multicolumn{7}{|c|}{ Pretreatment evaluation } & \multirow{3}{*}{$\begin{array}{c}\text { Treatment } \\
\text { 177Lu-DOTA-JR11 } \\
\text { total tumor } \\
\text { dose* (Gy) }^{\text {tos }}\end{array}$} & \multirow{2}{*}{\multicolumn{2}{|c|}{$\begin{array}{c}\text { Three-mo } \\
\text { follow-up CT }\end{array}$}} \\
\hline & & \multirow[b]{2}{*}{$\begin{array}{l}\text { CT tumor } \\
\text { volume } \\
\left(\mathrm{cm}^{3}\right)\end{array}$} & \multicolumn{3}{|c|}{${ }^{177}$ Lu-DOTATATE } & \multicolumn{3}{|c|}{ 177Lu-DOTA-JR11 } & & & \\
\hline & & & $\begin{array}{c}\text { Tumor dose } \\
\text { (Gy/GBq) }\end{array}$ & $\begin{array}{c}\mathrm{T} / \mathrm{K} \\
\text { ratio }\end{array}$ & $\begin{array}{l}\mathrm{T} / \mathrm{BM} \\
\text { ratio }\end{array}$ & $\begin{array}{c}\text { Tumor } \\
\text { dose } \\
\text { (Gy/GBq) }\end{array}$ & $\begin{array}{l}\mathrm{T} / \mathrm{K} \\
\text { ratio }\end{array}$ & $\begin{array}{l}\text { T/BM } \\
\text { ratio }\end{array}$ & & $\begin{array}{l}\text { Tumor } \\
\text { volume } \\
\left(\mathrm{cm}^{3}\right)\end{array}$ & $\begin{array}{c}\text { Tumor } \\
\text { reduction } \\
(\%)\end{array}$ \\
\hline \multicolumn{12}{|l|}{ Patient 1} \\
\hline 1 & LN & 23 & 2.0 & 1.6 & 22 & 7.4 & 3.3 & 56 & 59 & 13 & 45 \\
\hline 2 & LN & 1.7 & 1.2 & 0.9 & 13 & 7.0 & 3.1 & 53 & 31 & 1.5 & 13 \\
\hline 3 & LN & 22 & 1.4 & 1.1 & 15 & 5.7 & 2.5 & 44 & 47 & 5.9 & 73 \\
\hline 4 & LN & 0.4 & 1.1 & 0.9 & 12 & 5.9 & 2.6 & 45 & 23 & 0.1 & 80 \\
\hline 5 & LN & 0.9 & 2.0 & 1.6 & 22 & 7.4 & 3.3 & 56 & 39 & 0 & 100 \\
\hline \multicolumn{12}{|l|}{ Patient 2} \\
\hline 6 & Liver & 59 & 13 & 9.0 & 133 & 22 & 15 & 223 & 374 & 5.4 & 91 \\
\hline 7 & Liver & 66 & 6.3 & 4.4 & 65 & 29 & 20 & 294 & 487 & 29 & 56 \\
\hline 8 & Lung & 26 & 5.6 & 3.9 & 57 & 16 & 11 & 162 & 283 & 6.8 & 73 \\
\hline \multicolumn{12}{|l|}{ Patient 3} \\
\hline 9 & LN & 9.3 & 0.5 & 0.6 & 7.9 & 5.3 & 3.7 & 57 & 130 & 5.9 & 37 \\
\hline 10 & Liver & 26 & 2.7 & 3.6 & 43 & 5.9 & 4.1 & 63 & 33 & 25 & 5 \\
\hline 11 & Liver & 7.7 & 2.2 & 3.0 & 35 & 4.8 & 3.3 & 52 & 37 & 5.8 & 24 \\
\hline \multicolumn{12}{|l|}{ Patient 4} \\
\hline 12 & Liver & 0.4 & 4.6 & 3.2 & 68 & 20 & 9.3 & 245 & 302 & 0 & 100 \\
\hline 13 & Liver & 2.2 & 1.5 & 1.0 & 22 & 4.2 & 1.9 & 51 & 39 & 0.4 & 82 \\
\hline Median & & 9.3 & 2.0 & 1.6 & 22 & 7.0 & 3.3 & 56 & 47 & 5.8 & 73 \\
\hline $\begin{array}{l}\text { Interquartile } \\
\text { range }\end{array}$ & & $1.7-26$ & $1.2-4.6$ & $1.0-3.6$ & $15-57$ & $5.7-16$ & $3.1-9.3$ & $52-162$ & $37-283$ & $0.4-6.8$ & $37-82$ \\
\hline
\end{tabular}

*Total treatment activities were $6.1 \mathrm{GBq}$ for patient 1 (2 treatment cycles), $15.2 \mathrm{GBq}$ for patient 2 ( 3 treatment cycles), $5.9 \mathrm{GBq}$ for patient 3 (2 treatment cycles), and $13.7 \mathrm{GBq}$ for patient 4 (3 treatment cycles).

$\mathrm{T} / \mathrm{K}=$ tumor-to-kidney; T/BM = tumor-to-bone marrow; LN = lymph node.

Tumor volumes were calculated assuming ellipsoid shape. Respective tumor diameters were obtained from 3-dimensional CT reconstructions. Tumor doses were calculated using 3-dimensional voxel-based approach and are given as mean absorbed doses.

Sterile filtration of the final product was performed before application to the patient.

\section{Test Injection: Pharmacokinetics and Dosimetry}

Tumor and organ doses of ${ }^{177} \mathrm{Lu}$-DOTA-JR11 and ${ }^{177} \mathrm{Lu}$-DOTATATE were compared in the same patient using a cross-over design in an interval of $3 \mathrm{wk}$. Blood sampling, whole-body imaging studies, and SPECT/CT of the abdomen were used to generate pharmacokinetic data. All studies were done with the same SPECT/CT scanner (BrightView XCT; Philips) equipped with medium-energy, parallel-hole collimators. Whole-body scanning and low-dose SPECT/CT were performed at 1 , 3,24 , and $72 \mathrm{~h}$ after injection of a mean dose $( \pm \mathrm{SD})$ of $175 \pm 15 \mu \mathrm{g}$ (range, $160-200 \mu \mathrm{g})(1,060 \pm 75 \mathrm{MBq}$ [range, 990-1,130 MBq]) of ${ }^{177} \mathrm{Lu}$-DOTATATE and $150 \pm 20 \mu \mathrm{g}$ (range, 130-165 $\mu \mathrm{g}$ ) $(975 \pm 115$ MBq [range, 850-1,085 MBq]) of ${ }^{177}$ Lu-DOTA-JR11. One hour before injection of both radiopeptides, an infusion of $1,000 \mathrm{~mL}$ of physiologic $\mathrm{NaCl}$ solution containing $20.7 \mathrm{mg}$ of arginine per milliliter and $20.0 \mathrm{mg}$ of lysine per milliliter was started and continued for $5 \mathrm{~h}$ to inhibit tubular reabsorption of radiopeptides. The patient's vital parameters such as blood pressure, pulse rate, oxygen saturation, and electrocardiogram were monitored for at least $50 \mathrm{~min}$ after injection of ${ }^{177} \mathrm{Lu}$-DOTA-JR11.

To avoid organ- and tumor-activity overlap, a 3-dimensional quantification technique using SPECT/CT information was used for the calculation of tumor and kidney doses (IMALYTICS workstation and STRATOS software; Philips) (6). SPECT images were corrected for scatter and attenuation. A calibration factor was determined using a water-filled cylinder phantom with three ${ }^{177} \mathrm{Lu}$-filled spheres. Voxelwise residence time maps were calculated by integrating the time-activity curves using a monoexponential tail-fitting, and the mean absorbed tumor and kidney doses were calculated (7). Bone marrow doses were determined by blood-based red-marrow dose methodology (4). Blood samples were taken at 13 time points up to $22.5 \mathrm{~h}$ after injection. Urine samples were collected at 1.5, 3, 5, 8, and $21 \mathrm{~h}$ after injection to study the stability of ${ }^{177}$ Lu-DOTA-JR11. Two-dimensional dosimetry technique was used for the calculation of all remaining organs (OLINDA/EXAM 1.0 software; Microsoft) as described before (4).

\section{Treatment: Response and Adverse Events}

Patients received 2-3 cycles of ${ }^{177} \mathrm{Lu}-\mathrm{DOTA}-J R 11(105 \pm 35 \mu \mathrm{g}$ [range, $55-160 \mu \mathrm{g}][4,120 \pm 1,260 \mathrm{MBq}$ (range, $1,870-5,890 \mathrm{MBq})]$ per treatment cycle) in an interval of $8 \mathrm{wk}$. The amount of activity and number of treatment cycles was chosen on the basis of kidney dosimetry calculations. None of the patients received a kidney dose of more than 23 Gy. Kidney protection was performed in the same way as described above. The imaging and blood-sampling protocol were the same as for the test injections, with the same imaging and blood-sampling time points. As for the test 


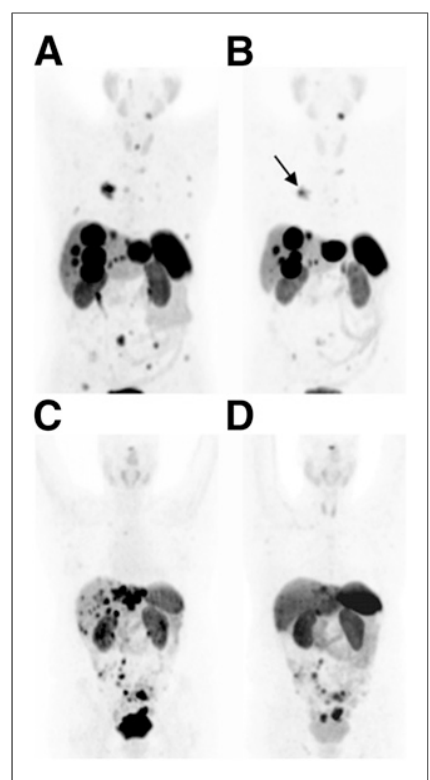

FIGURE 3. ${ }^{68} \mathrm{Ga}$-DOTATATE PET images of patient 2 before $(A)$ and 3 mo after (B) treatment with 15.2 GBq of ${ }^{177}$ Lu-DOTA-JR11 and ${ }^{68} \mathrm{Ga}-$ DOTATATE PET images of patient 3 before $(\mathrm{C})$ and $12 \mathrm{mo}$ after $(\mathrm{D})$ treatment with $5.9 \mathrm{GBq}$ of ${ }^{177} \mathrm{Lu}$-DOTAJR11. Three-month follow-up scan of patient 2 (B) shows decreased uptake by metastatic liver and bone disease and by primary tumor in right lung (arrow). Twelve-month follow-up scan of patient $3(\mathrm{D})$ shows decreased uptake by metastatic liver disease.

\section{RESULTS}

\section{Pharmacokinetics, Dosimetry, and Response}

The blood clearance was similar for ${ }^{177} \mathrm{Lu}-\mathrm{DOTA}-J \mathrm{R} 11$ and ${ }^{177} \mathrm{Lu}-$ DOTATATE: $\alpha$ half-life, $8 \pm 6$ min versus $10 \pm 6 \mathrm{~min}$, and $\beta$ halflife, $8.8 \pm 1.4 \mathrm{~h}$ versus $7.8 \pm 2.5 \mathrm{~h}$; approximately $65 \%$ of the administered activity was cleared in the $\alpha$ phase. Excretion was predominantly renal and no metabolites were found in the urine, indicating a high metabolic stability of ${ }^{177}$ Lu-DOTA-JR11. ${ }^{177} \mathrm{Lu}-$ DOTA-JR11 showed a longer intratumoral residence time and higher tumor uptake than ${ }^{177} \mathrm{Lu}$-DOTATATE in all 4 patients (between 1.3 and 2.8 times longer residence time and between 1.1 and 2.6 times higher tumor uptake), resulting in a 1.7-10.6 times higher tumor dose (Figs. 1 and 2). ${ }^{177}$ Lu-DOTA-JR11 has 1.1-7.2 times higher tumor-to-kidney and tumor-to-bone marrow dose ratios than ${ }^{177} \mathrm{Lu}$ DOTATATE. As a result, all 4 patients were treated with 2-3 treatment cycles of ${ }^{177} \mathrm{Lu}-\mathrm{DOTA}-J R 11$. Table 2 shows the results of tumor dose calculations, tumor-to-kidney dose ratios, tumor-tobone marrow dose ratios, and 3-mo follow-up. Table 1 and Figure 3 show the remission status before our treatment, after 3-mo of follow-up, and after maximum follow-up. Organ and effective doses of ${ }^{177} \mathrm{Lu}$-DOTA-JR11 and ${ }^{177} \mathrm{Lu}$-DOTATATE are given in Table 3.

\section{Adverse Events}

One patient experienced a short episode of flush just after injection of ${ }^{177} \mathrm{Lu}$-DOTA-JR11. Another patient developed grade
TABLE 3

Comparison of ${ }^{177}$ Lu-DOTATATE and ${ }^{177}$ Lu-DOTA-JR11 Organ and Effective Doses of 4 Patients with Neuroendocrine Tumors or Carcinomas

\begin{tabular}{|c|c|c|}
\hline Organ & ${ }^{177}$ Lu-DOTATATE & ${ }^{177}$ Lu-DOTA-JR11 \\
\hline Adrenals & $0.072 \pm 0.019$ & $0.11 \pm 0.024$ \\
\hline Brain & $0.061 \pm 0.018$ & $0.10 \pm 0.020$ \\
\hline Breasts & $0.061 \pm 0.018$ & $0.10 \pm 0.020$ \\
\hline Gallbladder wall & $0.070 \pm 0.020$ & $0.11 \pm 0.023$ \\
\hline GI (LLI wall) & $0.065 \pm 0.019$ & $0.11 \pm 0.021$ \\
\hline GI (small intestine) & $0.066 \pm 0.019$ & $0.11 \pm 0.021$ \\
\hline GI (stomach wall) & $0.069 \pm 0.020$ & $0.11 \pm 0.024$ \\
\hline GI (ULI wall) & $0.066 \pm 0.019$ & $0.11 \pm 0.021$ \\
\hline Heart wall & $0.065 \pm 0.019$ & $0.11 \pm 0.021$ \\
\hline Kidneys* & $1.2 \pm 0.35$ & $1.8 \pm 0.44$ \\
\hline Liver & $0.25 \pm 0.096$ & $0.33 \pm 0.16$ \\
\hline Lungs & $0.065 \pm 0.019$ & $0.11 \pm 0.021$ \\
\hline Muscle & $0.063 \pm 0.019$ & $0.10 \pm 0.020$ \\
\hline Ovaries & $0.056 \pm 0.009$ & $0.10 \pm 0.025$ \\
\hline Pancreas & $0.075 \pm 0.021$ & $0.12 \pm 0.027$ \\
\hline Red marrow & $0.079 \pm 0.018$ & $0.10 \pm 0.021$ \\
\hline Osteogenic cells & $0.22 \pm 0.053$ & $0.35 \pm 0.068$ \\
\hline Skin & $0.060 \pm 0.018$ & $0.10 \pm 0.019$ \\
\hline Spleen & $2.5 \pm 1.5$ & $3.0 \pm 2.3$ \\
\hline Thymus & $0.063 \pm 0.019$ & $0.10 \pm 0.020$ \\
\hline Thyroid & $0.062 \pm 0.019$ & $0.10 \pm 0.020$ \\
\hline Urinary bladder wall & $0.26 \pm 0.13$ & $0.37 \pm 0.21$ \\
\hline Uterus & $0.066 \pm 0.019$ & $0.11 \pm 0.021$ \\
\hline Total body & $0.083 \pm 0.021$ & $0.13 \pm 0.031$ \\
\hline $\begin{array}{l}\text { Effective dose } \\
\text { (Sv/GBq) }\end{array}$ & $0.15 \pm 0.046$ & $0.20 \pm 0.075$ \\
\hline
\end{tabular}

*Only kidney doses were calculated using 3-dimensional voxelbased technique. Range of kidney doses was $0.71-1.45 \mathrm{~Gy} / \mathrm{GBq}$ for ${ }^{177}$ Lu-DOTATATE and 1.44-2.27 Gy/GBq for ${ }^{177}$ Lu-DOTA-JR11.

GI = gastrointestinal; LLI = lower large intestine; ULI = upper large intestine.

Data are mean absorbed dose \pm SD in Gy/GBq.

3 thrombocytopenia $\left(41,000 / \mathrm{mm}^{3}\right)$, which completely recovered within 8 wk after injection of ${ }^{177}$ Lu-DOTA-JR11 (Table 1). There was no relevant decrease of tubular kidney function within $12 \mathrm{mo}$ of follow-up (mercaptoacetyltriglycine clearance, $135 \pm 11 \mathrm{~mL} /$ $\min / 1.73 \mathrm{~m}^{2}$ vs. $126 \pm 13 \mathrm{~mL} / \mathrm{min} / 1.73 \mathrm{~m}^{2}$ ). Also, creatinine levels did not much change before and approximately 12 mo after treatment $(1.32 \pm 0.13 \mathrm{mg} / \mathrm{dL}$ vs. $1.39 \pm 0.10 \mathrm{mg} / \mathrm{dL})$.

\section{DISCUSSION}

Our pilot study provided the first clinical evidence that radiolabeled sst antagonists may be superior to sst agonists for the treatment of neuroendocrine tumors. The sst $_{2}$-receptor antagonist ${ }^{177} \mathrm{Lu}$ DOTA-JR11 had a favorable pharmacokinetic and biodistribution profile (longer intratumoral residence time and higher tumor uptake) compared with the agonist ${ }^{177} \mathrm{Lu}$-DOTATATE, resulting in 1.7-10.6 times higher tumor doses. 
It is particularly encouraging that tumor-to-kidney and tumorto-bone marrow dose ratios were up to 6.2 and 7.2 times higher for the antagonist than for the agonist. The kidneys and the bone marrow are the major dose-limiting organs in peptide receptor radionuclide therapy (1). Therefore, severalfold higher tumor-tokidney and tumor-to-bone marrow dose ratios of ${ }^{177} \mathrm{Lu}$-DOTA-JR11 could significantly improve the efficacy and toxicity profile of radionuclide therapy when using only $50 \%$ of the cumulative activity of ${ }^{177} \mathrm{Lu}$-DOTATATE. According to our study results, the cumulative standard activity of $29.6 \mathrm{GBq}$ of ${ }^{177} \mathrm{Lu}$-DOTATATE (10) will result in a median tumor dose of $59 \mathrm{~Gy}$, a mean bone marrow dose of $2.3 \mathrm{~Gy}$, and a mean kidney dose of $36 \mathrm{~Gy}$. When treating patients with ${ }^{177} \mathrm{Lu}-\mathrm{DOTA}-J \mathrm{R} 11$, the median tumor dose will be $104 \mathrm{~Gy}$, the mean bone marrow dose will be $1.5 \mathrm{~Gy}$, and the mean kidney dose will be 27 Gy if using only $50 \%$ of the standard dose (14.8 $\mathrm{GBq}$ ) of ${ }^{177} \mathrm{Lu}$-DOTATATE. Actually, efficacy (2 patients with a partial response, 1 with stable disease, and 1 with a mixed response) and toxicity profiles (no grade 4 toxicity) are encouraging in our first 4 patients after treatment with ${ }^{177}$ Lu-DOTA-JR11.

The small number of patients is the most relevant limitation of this study. Nevertheless, the 3-dimensional voxel-based dosimetry approach together with the low-activity treatment approach in the same patient using a cross-over design allowed the direct comparison of ${ }^{177} \mathrm{Lu}-$ DOTA-JR11 and ${ }^{177} \mathrm{Lu}$-DOTATATE dosimetry in 13 tumor lesions.

\section{CONCLUSION}

This pilot study provided the first clinical evidence, to our knowledge, that treatment of neuroendocrine tumors with radiolabeled sst antagonists is clinically feasible. If the favorable tumor-to-organ dose ratios are confirmed in larger studies, radiopeptide treatment with sst antagonists may improve peptide receptor radionuclide therapy in neuroendocrine tumors. Systematic clinical studies with radiolabeled DOTA-JR11 for imaging and therapy of neuroendocrine tumors are in preparation.

\section{DISCLOSURE}

The costs of publication of this article were defrayed in part by the payment of page charges. Therefore, and solely to indicate this fact, this article is hereby marked "advertisement" in accordance with 18 USC section 1734. Jean E.F. Rivier, Jean Claude Reubi, and Helmut R. Maecke, who are coinventors of somatostatinbased antagonistic radiopeptides, assigned all their patent rights to their respective academic institutions. This work was supported by the Swiss National Science Foundation (320000-118333) and the German Cancer Consortium (DKTK). No other potential conflict of interest relevant to this article was reported.

\section{ACKNOWLEDGMENTS}

We thank the University Hospital Freiburg staff, in particular Christian Lohrmann, for reading the ${ }^{68} \mathrm{Ga}$-DOTATATE PET/CT scans and R. Tönnesmann for technical support. Jean E. F. Rivier is "The Dr. Frederik Paulsen Chair in Neurosciences Professor."

\section{REFERENCES}

1. van Essen M, Krenning EP, Kam BL, de Jong M, Valkema R, Kwekkeboom DJ. Peptide-receptor radionuclide therapy for endocrine tumors. Nat Rev Endocrinol. 2009;5:382-393.

2. Ginj M, Zhang H, Waser B, et al. Radiolabeled somatostatin receptor antagonists are preferable to agonists for in vivo peptide receptor targeting of tumors. Proc Natl Acad Sci USA. 2006;103:16436-16441.

3. Cescato R, Waser B, Fani M, Reubi JC. Evaluation of ${ }^{177}$ Lu-DOTA-sst2 antagonist versus ${ }^{177} \mathrm{Lu}$-DOTA-sst 2 agonist binding in human cancers in vitro. $\mathrm{J} \mathrm{Nucl}$ Med. 2011;52:1886-1890.

4. Wild D, Fani M, Behe M, et al. First clinical evidence that imaging with somatostatin receptor antagonists is feasible. J Nucl Med. 2011;52:1412-1417.

5. Fani M, Braun F, Waser B, et al. Unexpected sensitivity of sst2 antagonists to N-terminal radiometal modifications. J Nucl Med. 2012;53:1481-1489.

6. Wierts R, de Pont CD, Brans B, Mottaghy FM, Kemerink GJ. Dosimetry in molecular nuclear therapy. Methods. 2011;55:196-202.

7. Schweizer B, Schaefer A, Donsch P, et al. Evaluation of voxel-based dosimetry for targeted radionuclide therapies in phantom studies [abstract]. Eur J Nucl Med Mol Imaging. 2009;36(suppl 2):S428.

8. Wild D, Bomanji JB, Benkert P, et al. Comparison of ${ }^{68} \mathrm{Ga}$-DOTANOC and ${ }^{68} \mathrm{Ga}-$ DOTATATE PET/CT within patients with gastroenteropancreatic neuroendocrine tumors. J Nucl Med. 2013;54:364-372.

9. Bubeck B. Renal clearance determination with one blood sample: improved accuracy and universal applicability by a new calculation principle. Semin Nucl Med. 1993;23:73-86.

10. Kwekkeboom DJ, Teunissen JJ, Bakker WH, et al. Radiolabeled somatostatin analog [ ${ }^{177} \mathrm{Lu}$-DOTA0,Tyr3]octreotate in patients with endocrine gastroenteropancreatic tumors. J Clin Oncol. 2005;23:2754-2762. 